\title{
Insulin-Like Growth Factor 2 Receptor Is an IFN $\gamma$-Inducible Microglial Protein that Facilitates Intracellular HIV Replication
}

\section{Implications for HIV-Induced Neurocognitive Disorders}

\author{
Hyeon-Sook Suh, ${ }^{*}$ Melissa Cosenza-Nashat, ${ }^{*}$ \\ Namjong Choi, ${ }^{*}$ Meng-Liang Zhao, ${ }^{*}$ Jiu-feng Li, ${ }^{\dagger}$ \\ Jeffrey W. Pollard, ${ }^{\dagger}$ Randy L Jirtle, ${ }^{\ddagger}$ \\ Harris Goldstein, ${ }^{\S}$ and Sunhee C. Lee* \\ From the Departments of Pathology," Developmental and \\ Molecular Biology, ${ }^{\dagger}$ and Microbiology and Immunology, ${ }^{\S}$ Albert \\ Einstein College of Medicine, Bronx, New York; and the \\ Department of Radiation Oncology, ${ }^{\ddagger}$ Duke University Medical \\ Center, Durbam, North Carolina
}

Insulin-like growth factor 2 receptor (IGF2R), also known as cation-independent mannose 6-phosphate (M6P) receptor, is a transmembrane glycoprotein localized in the trans-Golgi region and is involved in targeting both M6P-bearing enzymes and IGF2 to the lysosomal compartment. During development, IGF2R plays a crucial role in removing excess growth factors from both tissue and blood. Due to the perinatal lethality of the global $\operatorname{Igf} 2 r$ knockout, the function of IGF2R in adults, particularly in the CNS, is not known. We made a novel observation that IGF2R is highly expressed in microglial nodules in human brains with HIV encephalitis. In vitro, microglial IGF2R expression was uniquely enhanced by IFN $\gamma$ among the several cytokines and TLR ligands examined. Furthermore, in several in vitro models of HIV infection, including human and murine microglia, macrophages, and nonmacrophage cells, IGF2R is repeatedly shown to be a positive regulator of HIV infection. IGF2R RNAi also down-regulated the production of the IP-10 chemokine in HIV-infected human microglia. Injection of VSVg env HIV into mouse brain induced HIV p24 expression in neurons, the only cell type normally expressing IGF2R in the adult brain. Our results demonstrate a novel role for IGF2R as an inducible microglial protein involved in regulation of HIV and chemokine expression. Mice with the $C s f 1 r$-driven $\operatorname{Ig} f 2 r$ knockout should be useful for the investigation of macrophage-specific IGF2R function. (Am J Pathol 2010, 177:2446-2458; DOI: 10.2353/ajpath.2010.100399)

The insulin-like growth factor (IGF) system consists of growth peptides (insulin, IGF1 and IGF2), their receptors (insulin receptor, IGF1R and IGF2R), and circulating binding proteins (IGFBPs $1-7) \cdot{ }^{1-3}$ Ligand binding activates the cytoplasmic protein tyrosine kinases of IGFrelated receptors (IGF1R and insulin receptor) which then stimulates an intracellular cascade of signaling pathways, leading to the growth and metabolic effects. ${ }^{2,4}$ In contrast, aside from rare reports, ${ }^{5}$ IGF2R is not known to transduce signals. ${ }^{6}$ IGF2R is a large molecule $(\sim 300$ $\mathrm{kDa}$ ) with a bulky extracellular domain with binding sites for IGF2 and mannose-6-phosphate (M6P), and a short cytoplasmic tail with amino acid sorting motifs. ${ }^{6}$ The main physiological functions of IGF2R are i) regulation of circulating and tissue IGF2 levels ${ }^{7,8}$ and ii) trafficking of newly synthesized M6P-containing lysosomal enzymes from the trans-Golgi network to lysosomes, hence the name cation-independent M6P receptor (MPRci). ${ }^{6,9,10}$ This latter function is shared by another M6P receptor, the cation-dependent M6P receptor (MPRcd). In addition to the high affinity binding between the cognate receptors and the ligands, there is also a low affinity $(\sim 1 / 10)$ binding among other members of the receptors and li-

Supported by National Institutes of Health grants K01 MH084705, RO1 MH55477, RO1 CA131270, PO1 CA100324, Einstein CFAR P30 Al051519, and a CFAR pilot grant.

Accepted for publication July 15, 2010

A guest editor acted as editor-in-chief for this manuscript. No person at Thomas Jefferson University or Albert Einstein College of Medicine was involved in the peer review process or final disposition for this article.

Address reprint requests to Hyeon-Sook Suh, M.D., Department of Pathology, Albert Einstein College of Medicine, 1300 Morris Park Avenue, Bronx NY 10461. E-mail: hyeon-sook.suh@einstein.yu.edu. 
gands of the IGF family. For example, IGF2 binds to IGF1R and insulin receptor, and IGF1 binds to IGF2R and insulin receptor. ${ }^{4,11}$

During development, IGF2R plays an essential role in degrading extracellular IGFs, preventing its binding and signaling through IGF1R and insulin receptor, as shown in global lgf2r KO mice that are perinatally lethal due to organ overgrowth. ${ }^{7,12,13}$ However, due to the perinatal lethality of the $\mathrm{KO}$ mice, the postnatal function of this receptor is largely unknown. A cell type-specific or organ-specific deletion of IGF2R is necessary to determine the postnatal function of this receptor in physiological and pathological processes. For example, Wylie et al have investigated liver- and skeletal muscle-specific Igf2r functions by creating organ-specific KO mice using the Cre-lox technology. ${ }^{14}$

The importance of the IGF system in the maintenance of healthy brain function is widely recognized..$^{1,15}$ In normal CNS, neurons express abundant IGF2R but other cells are devoid of IGF2R expression. ${ }^{16}$ IGF2R expression has been examined in a few human neurological conditions, and these studies reported various results ranging from a lack of expression in multiple sclerosis plaques $^{16}$ to expression in reactive astrocytes in senile plaques of Alzheimer's brains. ${ }^{17}$ In the periphery, various viral infections have been associated with abnormal IGF systems. Specifically, reduced serum IGF1 and IGF2 levels have been found in individuals with HIV infection (and associated with disease progression), as well as infection with other viruses (herpes simplex virus, cytomegalovirus, rotavirus and adenovirus). ${ }^{18-21}$ Furthermore, reduced IGF2 expression is reported in the brains of SHIV-infected macaques. ${ }^{22}$ Despite many studies suggesting a link between the IGF system and the pathogenesis of CNS diseases including HIV infection, ${ }^{23-25}$ there are no studies specifically examining the role of IGF2R in CNS infections.

Our study was inspired by an observation that IGF2R expression was robustly induced in microglial nodules in HIV encephalitis (HIVE). In the current study, we extended these findings in HIVE and further tested the hypothesis that IGF2R is an inducible microglial protein that plays a role in viral infection and inflammation. Our results indeed reveal a novel role for IGF2R as an inducible microglial protein involved in intracellular HIV replication. IGF2R might be considered as a new therapeutic target for HIV/AIDS.

\section{Materials and Methods}

\section{Human Brain Tissues}

Postmortem human brain tissue sections were obtained from the National NeuroAIDS Tissue Consortium (NNTC). They consisted of paraffin-embedded sections of frontal cortex and white matter from $\mathrm{HIV}^{-}$individuals $\left(\mathrm{HIV}^{-}\right)$, $\mathrm{HIV}^{+}$individuals with or without HIV encephalitis (HIVE and $\mathrm{HIV}^{+}$, respectively). The number of cases examined were $\operatorname{HIV}^{-}(n=5), \operatorname{HIV}^{+}(n=5)$, and $\operatorname{HIVE}(n=7)$.
Detailed clinical and postmortem pathological information on the cases are previously described. ${ }^{26,27}$

\section{Tissue Immunohistochemistry}

We used standard immunohistochemistry methods for paraffin-embedded tissue sections using antigen-retrieval by heat treatment in citrate buffer, as described. ${ }^{27}$ The affinity purified rabbit anti-IGF2R/MPRci (HL5299) was obtained from Dr. Peter Lobel, Rutgers University, NJ. The antibody was raised against the extracellular domain of the bovine IGF2R. HIV infection was determined by anti-HIV gag p24 stain. Double labeling with cell-specific markers was performed for CD68 (lysosomal marker of microglia and macrophages), CD45 (membrane marker for macrophages, microglia, and lymphocytes), GFAP (astrocytes-specific intermediate filament protein), and neuN (neuronal nuclear protein). Mouse anti-neuN IgG1 (clone A60) was purchased from Millipore (Temecula, CA) and was used at 1:500. Procedures for other antibodies are previously published. ${ }^{27}$ We combined labeled secondary (peroxidase-labeled or alkaline phosphatase-labeled) antibodies with various chromogens (diaminobenzidine, nitroblue tetrazolium and VIP) to develop brown, blue, or red color.

\section{ImageJ Analysis}

For quantitative analysis of IGF2R immunostain, singlelabeled slides were analyzed for the percent positive area stained with the $\mathrm{NIH} \mathrm{ImageJ} \mathrm{software,} \mathrm{as} \mathrm{previously}$ described. ${ }^{27}$ Because IGF2R is normally expressed in neurons but not in white matter, white matter areas were randomly photographed at $\times 400$ magnification (15-20 per case) from a total of 14 cases. Three cases were excluded from analysis due to high background staining which interfered with image analysis.

\section{MeWo Cells}

MeWo cells (stable IGF2R knocked down melanoma cell lines: KD), ${ }^{28}$ and control MeWo cells (WT) were generously provided by Dr. Michael Gershon, Columbia University, NY. Single cell suspension was plated at 1-10 $\times$ $10^{6}$ cells per $\mathrm{ml}$ in DMEM supplemented with $5 \%$ FCS and penicillin $(100 \mathrm{U} / \mathrm{ml})$, streptomycin $(100 \mu \mathrm{g} / \mathrm{ml})$, and fungizone $(0.25 \mu \mathrm{g} / \mathrm{ml}$ ) (Gibco, now Invitrogen, Carlsbad, $\mathrm{CA})$, in the presence of $2 \mu \mathrm{g} / \mathrm{ml}$ puromycin.

\section{Human Fetal Microglial Culture}

Human CNS cell cultures were prepared from human fetal abortuses as described. ${ }^{29}$ All tissue collection was approved by the Albert Einstein College of Medicine Institutional Review Board. Primary mixed CNS cultures were prepared by enzymatic and mechanical dissociation of the cerebral tissue followed by filtration through nylon meshes of 230- and $130-\mu \mathrm{m}$ pore sizes. Single 
cell suspension was plated at $1-10 \times 10^{6}$ cells per ml in DMEM supplemented with 5\% FCS and antibiotics for 2 weeks, and then microglial cells were collected by aspiration of the culture medium. Monolayers of microglia were prepared in 60-mm tissue culture dishes at $1-2 \times 10^{6}$ cells per $5 \mathrm{ml}$ medium or in 96-well tissue culture plates at $1-2 \times 10^{4}$ cells per $0.1 \mathrm{ml}$ medium per well. Two to four hours later, cultures were washed to remove nonadherent cells (neurons and astrocytes). Microglial cultures were highly pure consisting of $>98 \% \mathrm{CD} 8^{+}$cells.

\section{Generation of the Csf1r-lgf2r KO Mice}

To create macrophage-specific lgf2r KO mice, a transgenic mouse line in which Cre recombinase is expressed under the promoter and the upstream enhancer of the CSF-1 receptor gene (Csf1r) to direct macrophage-specific expression, designated Tg(Csf1r-icre)1jwp (gift of Dr. Jeffrey W. Pollard, Albert Einstein College of Medicine) was used. Female mice of mixed genetic background (Sv129/C57BI), heterozygous for the floxed lgf2r exon $10,{ }^{14}$ were obtained from Dr. Randy Jirtle, Duke University and were crossed with male Csf1r Cre mice to create litters in which $50 \%$ inherited a floxed allele and another $50 \%$ a wild-type (WT) allele maternally. Because the mouse (but not human) IGF2R paternal allele is normally silenced through imprinting, this strategy is expected to produce macrophage-specific KO mice and WT littermates at equal ratios. A PCR-based assay was used to determine the presence of the loxP site in IGF2R intron 9 as previously described. ${ }^{14}$

\section{Isolation of Bone Marrow-Derived Macrophages (BMDM) from Csf1r-Igf2r KO and WT Mice}

BMDM were isolated following a standard protocol. Briefly, femur and tibia were flushed and cell pellets were prepared in Hanks' balanced salt solution. Cells were resuspended and cultured in 60-mm plastic Petri dish in DMEM with 10\% FCS and antibiotics, supple- mented with $10,000 \mathrm{U} / \mathrm{ml}$ of recombinant human M-CSF (R\&D, Minneapolis, MN) for 10-14 days. Real-time PCR was performed to confirm the presence or absence of Igfar mRNA expression in the KO and WT macrophage cultures.

\section{Preparation of Murine Microglia and Astrocyte Cultures}

Murine microglia and astrocyte cultures were established from the neonatal (P1) brains using the standard protocol with minor modifications. ${ }^{30,31}$ Briefly, brains were freed of meninges and then gently triturated using plastic pipettes. Cell suspensions were then incubated with tryp$\sin /$ EDTA at $37^{\circ} \mathrm{C}$ for 25 minutes, washed, and filtered through the $100 \mu \mathrm{m}$ nylon mesh. The mixed single cell suspensions were plated at a density of $10^{5}$ cells per ml in complete medium (DMEM 5\% FCS with antibiotics). Ten to 14 days later, microglia were pooled by gently tapping the dish and collecting the floating cells, as described for human microglia. They were resuspended and reseeded in fresh medium supplemented with $\mathrm{M}$ CSF. Astrocyte cultures were generated by repeatedly trysinizing the remaining monolayer until the cultures were devoid of $\mathrm{CD} 11 \mathrm{~b}^{+}$microglia.

\section{HIV Infection}

MeWo cells, human microglia, murine BMDM, murine microglia, and astrocyte cultures were infected with single-cycle competent, vesicular stomatitis virus (VSVg) env pseudotyped HIV, as previously described. ${ }^{32}$ VSVg env HIV was produced by cotransfecting 293T cells with pHIV $_{\text {NL4.3 }}$ (Nef-intact, Vpr-intact, Env-deficient, gift of Dr. Maurizio Federico ${ }^{33}$ ) and pVSVg env. Cells were infected with $\sim 40 \mathrm{ng} / \mathrm{ml} \mathrm{p} 24$ viral input that resulted in $25 \%$ to $50 \%$ cell infection at three days post inoculation, unless otherwise indicated. For electron microscopy of progeny HIV virions in MeWo cells, chimeric env HIV were generated by cotransfecting 293T cells with pHIV $\mathrm{NL4.3}_{\text {(Env-intact) }}$ and pVSVg env. The resulting virus has both HIV and VSVg env proteins.

Table 1. Human and Mouse Primers Used for Q-PCR

\begin{tabular}{|c|c|c|}
\hline Gene & Primer (forward) & Primer (backward) \\
\hline \multicolumn{3}{|c|}{ Human primers } \\
\hline GAPDH & $5^{\prime}$-CGCTCAATGACAATTTCGTG-3' & $5^{\prime}-$ ACCCGGTGACTGTAGCCATA-3' \\
\hline$P B D A$ & 5'-ACGATCCCGAGACTCTGCTTC-3' & $5^{\prime}-$ GCACGGCTACTGGCACACT-3' \\
\hline IGF2R & $5^{\prime}$-GAAGGTGAAGGTCGGAGT-3' & 5'-GAAGATGGTGATGGGATTTC-3' \\
\hline HIV gag & 5'-TGCTATGTCAGTTCCCCTTGGTTCTCT-3' $(40)$ & $5^{\prime}$-AGTTGGAGGACATCAAGCAGCCATGCAAAT-3' \\
\hline \multicolumn{3}{|c|}{ - } \\
\hline Gapdh & $5^{\prime}-$ TTGATGGCAACAATCTCCAC-3' & 5'-CGTCCCGTAGACAAAATGGT-3' \\
\hline$b$-actin & $5^{\prime}-$ TGCACCACCAACTGCTTAG- $3^{\prime}$ & $5^{\prime}$-GGATGCAGGGATGATGTTC-3' \\
\hline $\operatorname{lgf2r}$ & $5^{\prime}$-GGGAAGCTGTTGACTCCAAAA-3' & 5'-GCAGCCCATAGTGGTGTTGAA-3' \\
\hline $\operatorname{lgf1}$ & $5^{\prime}-$ CTGGACCAGAGACCCTTTGC-3' & 5'-GGACGGGGACTTCTGAGTCTT-3' \\
\hline lgf2 & 5'-GTGCTGCATCGCTGCTTAC-3' & 5'-ACGTCCCTCTCGGACTTGG-3' \\
\hline Igftr & 5'-GTGGGGGCTCGTGTTTCTC-3' & 5'-GATCACCGTGCAGTTTTCCA-3' \\
\hline MPRcd & $5^{\prime}$-CAAAGAACGAGGTGGCTCTC-3' & 5'-CCCAACCACTGTCTCCTTGT-3' \\
\hline lba-1 & 5'-TGATGAGGATCTGCCGTCCAAACT-3' & 5'-TCTCCAGCATTCGCTTCAAGGACA-3' \\
\hline Gfap & 5'-TTTCTCGGATCTGGAGGTTG-3' & $5^{\prime}$-AGATCGCCACCTACAGGAAA-3' \\
\hline
\end{tabular}




\section{Intracerebral Injection of HIV}

To determine whether IGF2R has a similar HIV-enhancing role in vivo, we performed intracerebral injection of VSVg env HIV to WT and KO mice. Briefly, $10 \mu \mathrm{l}$ of VSVg env HIV ( $200 \mathrm{ng} / \mathrm{ml}$ p24) was injected manually to the right caudate-putamen of approximately 8-week-old WT ( $n=$ $5)$ and $\mathrm{KO}$ mice $(n=4)$. All mice recovered from anesthesia and appeared normal, except one which developed hemiparesis. This mouse was excluded from the analysis. The mice were sacrificed 7 days later, and the right cerebral hemispheres were processed for real timePCR (Q-PCR) analysis. Brains from additional mice were also examined by H\&E and p24 immunohistochemistry after fixation in formalin and paraffin embedding.

\section{RNA Interference with IGF2R-Specific siRNA}

Human microglia in 60-mm dishes were transfected with $10 \mathrm{nmol} / \mathrm{L}$ or $30 \mathrm{nmol} / \mathrm{L}$ human IGF2R-specific small interfering RNA (siRNA) or control nontargeting siRNA (Dharmacon, Chicago, IL) with TransIT-TKO transfection reagents from Mirus following the manufacturer's instructions, as previously described. ${ }^{34,35}$ After incubation for 48 to 72 hours, cells were washed with fresh medium and then infected with HIV or treated with stimulants for 6 hours to 48 hours. IGF2R knockdown was confirmed by Q-PCR.

\section{Treatment of Cultures with Cell Stimulants}

Cultures were treated with recombinant human or murine cytokines at $10 \mathrm{ng} / \mathrm{ml}$ or TLR ligands (LPS $100 \mathrm{ng} / \mathrm{ml}$ or poly IC $10 \mu \mathrm{g} / \mathrm{ml}$ ), as previously described. ${ }^{32,32,36}$ Soluble M6P was purchased from Sigma-Aldrich and was used at a concentration of $0.1-10 \mathrm{mmol} / \mathrm{L}$.

\section{Ultrastructural Analysis of HIV Virions}

MeWo cells plated at $10^{6}$ per $100-\mathrm{mm}$ dish that reached $\sim 50 \%$ confluence were infected with HIV for 3 days. Cells were washed with serum-free medium, fixed with the Trump solution, and then processed for transmission electron microscopy, as previously described. ${ }^{37}$

\section{Western Blot Analysis}

IGF2R is a high molecular weight ( $\sim 300 \mathrm{kDa})$ protein and protein transfer can be susceptible to experimental conditions. ${ }^{38}$ Therefore, Western blot analysis was performed under nonreducing conditions. Thirty to seventy micrograms of protein was separated by 6 or $8 \%$ SDSPAGE and then transferred to polyvinylidene difluoride membrane. The blots were blocked in Tris-buffered saline$0.1 \%$ Tween-20 containing 5\% nonfat milk and then incubated with antibodies at $4^{\circ} \mathrm{C}$ for 16 hours. Primary Antibodies included: rabbit anti-human IGF2R antibody 1/500 (gift of Carolyn Scott) ${ }^{39}$; anti-p24 gag, 1/500 (DakoCytomation, Carpinteria, CA); total Stat3, 1/1000 and $\beta$-actin, 1/3000 (Santa Cruz Biotechnology, Santa Cruz, CA). Secondary antibodies were horseradish peroxidase-conjugated antimouse or anti-rabbit IgG and were used at 1:2000 to 1:10,000 for 1 hour at room temperature. Signals were developed using enhanced chemiluminescence (Pierce Biotechnology, Rockford, IL). Densitometric analysis was performed using Scion NIH Image software (Scion, Frederick, MD).

\section{Real-Time PCR}

Quantitative real-time reverse transcription-PCR was performed as described previously ${ }^{32,32,34}$ Briefly, total RNA was extracted with TRIzol (Invitrogen Life Technologies, Carlsbad, CA), following the manufacturer's instructions. PCR was performed using a SYBR green PCR mix and conducted with the ABI Prism 7900HT (Applied Biosystems, Carlsbad, CA). All values were expressed as the increase relative to the expression of glyceraldehyde-3-phosphate dehydrogenase (GAPDH) or porphobilinogen deaminase (PBDA). The mean value of the replicates for each sample was calculated and ex-
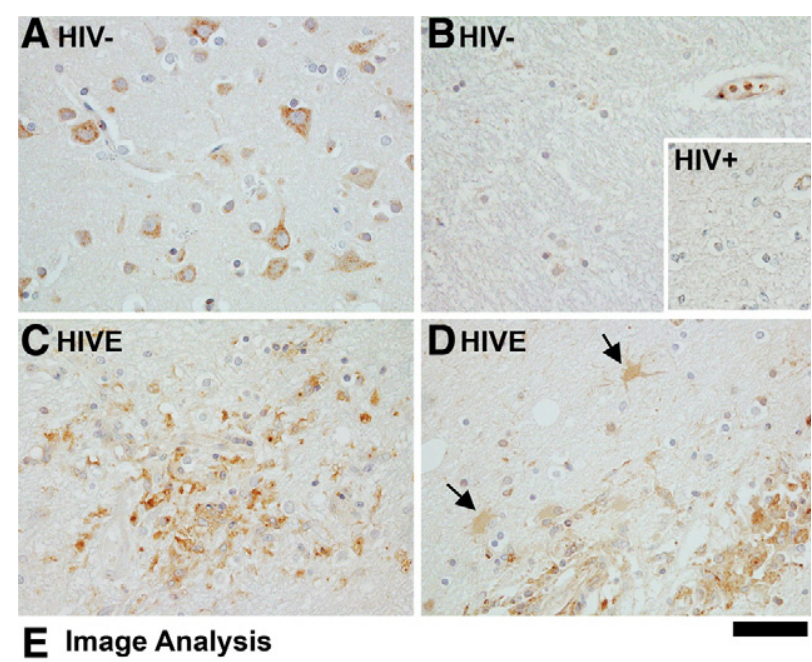

E Image Analysis

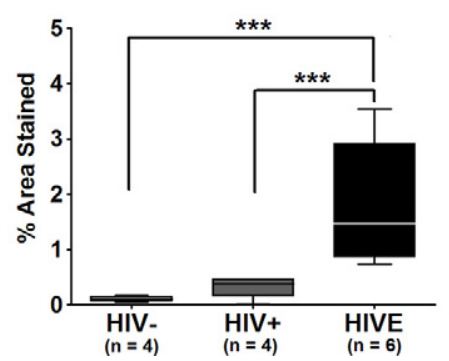

Figure 1. IGF2R expression is up-regulated in macrophages and microglia in HIVE. A rabbit anti-bovine IGF2R antibody was used to study the expression of IGF2R in postmortem human brain sections. A: All cases exhibited neuronal IGF2R expression regardless of their HIV status (shown for $\mathrm{HIV}^{-}$). B: White matter of $\mathrm{HIV}^{-}$and $\mathrm{HIV}^{+}$(inset) brains showed little or no staining for IGF2R, while leukocytes within the blood vessels show positivity. C: HIVE cases displayed abundant IGF2R staining especially in areas of HIV infection (microglial nodules). The majority of $\mathrm{IGF}^{+} \mathrm{R}^{+}$cells were microglia and macrophages, based on morphology. D: Some reactive astrocytes in HIVE were also positive (arrows). E: A subset of cases were analyzed for the percent area immunoreactive for IGF2R using an image analysis computer program (NIH ImageJ). $\mathrm{HIV}^{+}$cases and $\mathrm{HIV}^{-}$had significantly lower levels of immunoreactivity $(P<0.001)$ compared to HIVE cases. While there was a trend for $\mathrm{HIV}^{+}$cases to have slightly higher levels of immunoreactivity than $\mathrm{HIV}^{-}$, this did not reach significance. The line in the box indicates the median and the whiskers indicate range. The box indicates the quartiles (25th and 75 th). Scale bar: $50 \mu \mathrm{m}(\mathbf{A}-\mathbf{D}) .{ }^{* * * *} P<0.001$. 
pressed as the cycle threshold (Ct; cycle number at which each PCR reaches a predetermined fluorescence threshold, set within the linear range of all reactions). The amount of gene expression was then calculated as the difference between the $\mathrm{Ct}$ of the sample for the target gene and the mean $\mathrm{Ct}$ of that sample for the endogenous control. Each assay was performed in triplicate. The primer sequences for both human and mouse genes are listed in Table 1. ${ }^{40}$

\section{Statistical Analysis}

Results shown are representative of two to five separate experiments using cells from different brain cases. For certain experiments, results from multiple separate experiments were pooled after data were normalized to the baseline value. For statistical analysis, Student's $t$-test or one-way analysis of variance (analysis of variance) with Dennett's post test was performed to determine whether there were significance differences between the experimental and control groups.

\section{Results \\ IGF2R Is Expressed Robustly in Microglial Nodules within HIV Encephalitic Brains}

We examined the expression of IGF2R in human brain sections from individuals with HIVE or controls (HIV-seronegative and HIV-seropositive). As shown in Figure 1A, IGF2R was constitutively expressed in neurons in all brains. White matter of $\mathrm{HIV}^{-}$and $\mathrm{HIV}^{+}$brains showed little or no staining for IGF2R (Figure 1B and data not shown); however, HIVE cases displayed abundant IGF2R staining in microglial nodules as well as in diffusely scattered glial cells which had no obvious relationships with microglial nodules (Figure $1 \mathrm{C}$ and data not shown). By morphology, the IGF2R ${ }^{+}$cells were neurons, macrophages, microglia, as well as occasional astrocytes (Figure 1D). In addition, ependymal cells were also positive (not shown). Quantitative analysis of IGF2R immunoreactivity was performed in a subset of cases singlely labeled for the receptor, using the NIH ImageJ software (Figure 1E). The results showed that HIVE cases had much larger percentage of the brain area immunoreactive for IGF2R
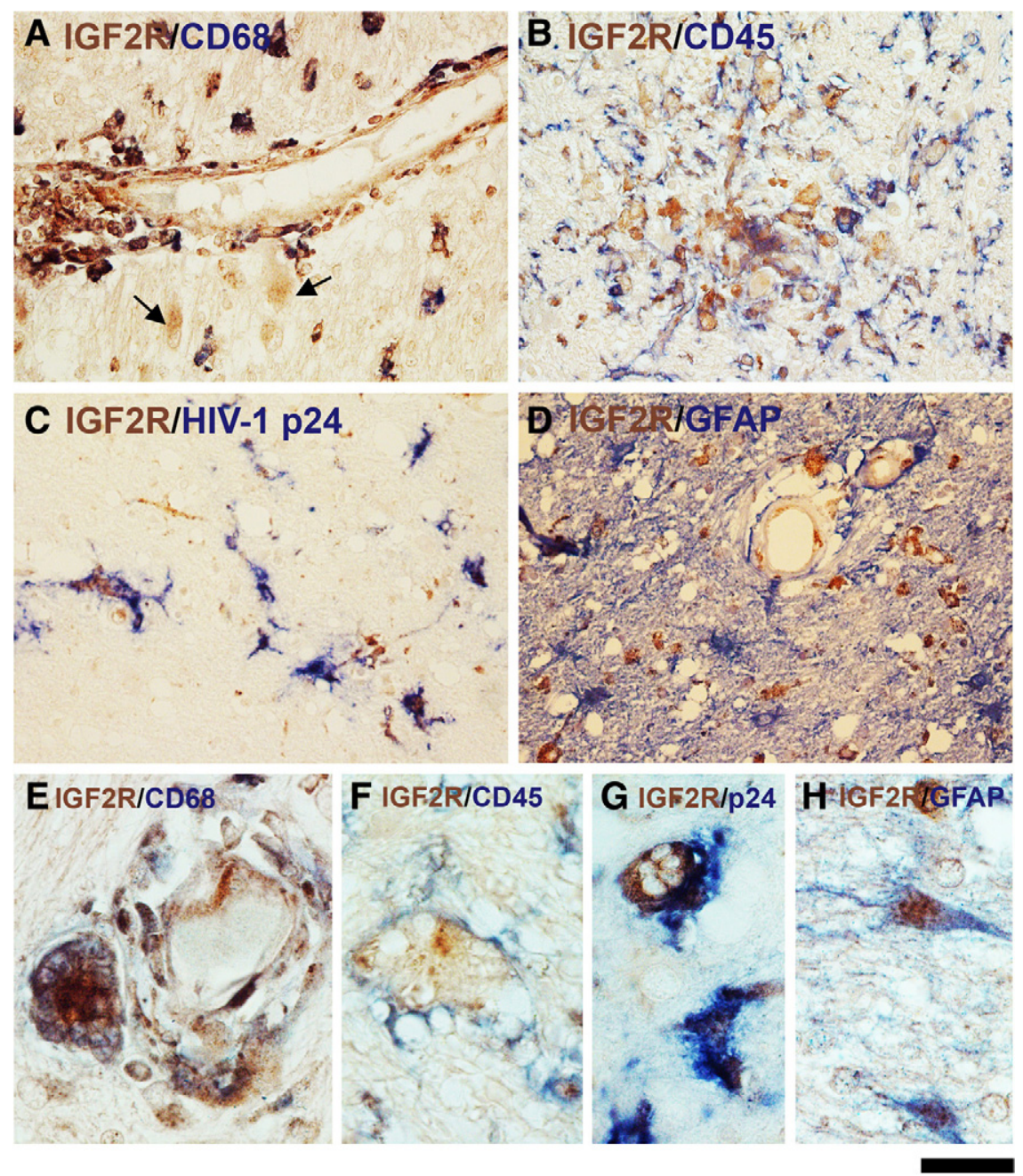
and cellular/viral markers in HIVE. To confirm the identity of IGF $2 \mathrm{R}^{+}$cells, double immunohistochemistry for a series of glial markers was performed. Diaminobenzidine (brown) was used to mark IGF2R, and nitroblue tetrazolium (blue) was used for the cell-specific markers. A Double label with CD68 shows many double positive cells outside the vessels. They have the shape of macrophages. Also note a cluster of smaller positive cells within the vessel to the left. CD68-/IGF2R ${ }^{+}$cells (arrows) in the vicinity have the shape of astrocytes. B: Anti-CD 45RB was used to mark many process-bearing microglia as well as some round macrophages in this microglial nodule. A subset of $\mathrm{CD} 45^{+}$cells are also IGF2R ${ }^{+}$. C: Staining with an HIV-1 p24 antibody shows many double-labeled, processbearing cells in this field. D: Double labeling with GFAP and IGF2R shows GFAP ${ }^{+}$astrocytes are not generally positive for IGF2R. ( $\mathbf{E}, \mathbf{F}$, and G) High-power images of multinucleated giant cells coexpressing IGF2R (intracellular) and the markers CD68 (intracellular), CD45 (cell membrane), and HIV-1 p24 (intracellular), respectively. H: High-power view of rare $\mathrm{IGF}^{+} \mathrm{R}^{+}$ $\mathrm{GFAP}^{+}$astrocytes showing different subcellular localization of the two chromogens. Scale bar: $50 \mu \mathrm{m}(\mathbf{A}-\mathbf{D}) ; 20 \mu \mathrm{m}(\mathbf{E}-\mathbf{H})$. 
compared to $\mathrm{HIV}^{-}$and $\mathrm{HIV}^{+}$control cases $(P<0.001$, analysis of variance).

Double labeling with cell-specific markers confirmed that the majority of IGF2R immunoreactive cells in the white matter of HIVE were microglia and macrophages $\left(\mathrm{CD} 8^{+}, \mathrm{CD} 45^{+}\right)$(Figure 2, A, B, E, F). In addition, some reactive astrocytes $\left(\mathrm{GFAP}^{+}\right)$were also positive for IGF2R in some cases (Figure 2, D and H). Double labeling for HIVgag (p24) demonstrated that a subset of IGF2R ${ }^{+}$ macrophages and microglia were also $\mathrm{HIV}^{+}$(Figure 2, C and $\mathrm{G}$ ).

\section{Role of IGF2R in HIV Replication in IGF2R kDa MeWo Cells}

IGF2R is an endosomal protein that is expressed in all cells. The marked enhancement of IGF2R expression colocalizing with microglial nodules in HIVE led us to ask whether IGF2R plays a role in HIV infection. We examined the amount of HIV expression in cultures of human melanoma cells stably expressing IGF2R siRNA (MeWo cells), generously provided by Dr. Michael Gershon. ${ }^{28}$ We also tested the effect of M6P (10 mmol/L) on WT MeWo cells. Results of Western blot analysis are shown in Figure 3 (A and B). A representative immunoblot (A) and pooled densitometric analysis from three separate experiments (B) demonstrate that IGF2R KD MeWo cells indeed showed reduced expression of IGF2R (albeit partial), and that these cells also showed reduced amount of HIV gag. M6P treatment of WT MeWo cells showed further increase of both IGF2R and HIV gag expression, although not statistically significant. These results suggested that IGF2R facilitated HIV replication.

We next asked whether disruption of IGF2R-mediated endosomal trafficking alters HIV virion morphogenesis. MeWo cells were infected with HIV bearing chimeric env (HIV and VSVg env, see Materials and Methods), and transmission electron microscopy was performed to compare virion morphology in WT and IGF2R KD cultures. As shown in Figure 3 (C and D), in MeWo cells (epithelial cells), HIV virions were found exclusively in the extracellular space. Although there was an impression that fewer virions were generated in KD culture compared to WT culture, no differences in virion morphology were observed between the two cultures.

\section{IFNy Up-Regulates IGF2R Expression in Microglia}

Having established that IGF2R expression undergoes dramatic increase from barely detectable (in normal) to highly expressed (in HIVE) in glia, we next asked whether inflammatory mediators and/or HIV are responsible for IGF2R up-regulation, using well-established primary human fetal CNS cultures. We first determined the baseline IGF2R expression by immunofluorescence confocal microscopy. Figure 4A shows cultured human microglia
A
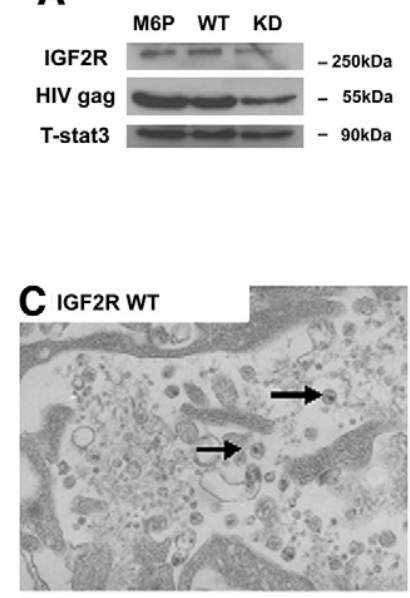

B
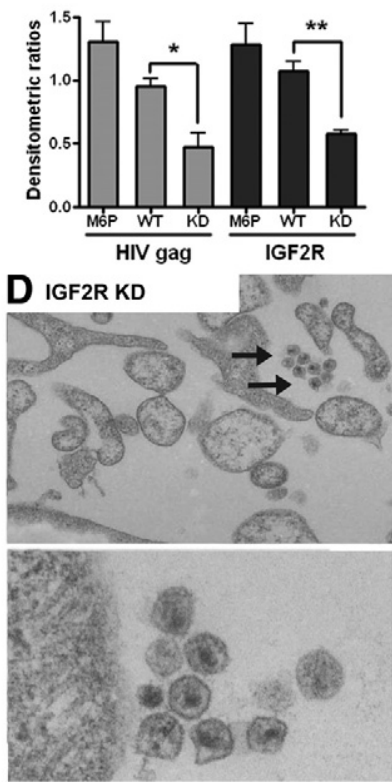

Figure 3. Role of IGF2R in HIV expression in MeWo cells. MeWo cells (human melanoma cell lines) stably expressing IGF2R siRNA (KD) and control (WT) are infected with HIV-bearing VSVg env (A and B) or chimeric env (both $\mathrm{HIV}^{-}$and VSVg env: $\mathbf{C}$ and $\mathbf{D}$ ), as described in the Materials and Methods. A and B: The amount of HIV gag expression was examined by Western blot. Densitometric ratios from three separate cultures showed that HIV gag expression was significantly inhibited in MeWo cells with IGF2R siRNA (KD) compared to WT cells (mean \pm SEM, $P<0.05 t$-test). M6P (10 $\mathrm{mmol} / \mathrm{L}$ ) treatment of WT cells increased HIV expression (though not significant), probably through up-regulation of IGF2R. C and D: Electron microscopy of HIV-infected MeWo cells showed HIV particles (arrows) with characteristic morphology (eccentric cores, irregular shapes, and sizes) in extracellular spaces near cell processes. Although virions appear less frequent in $\mathrm{kDa}$ cultures compared to WT cultures, no difference in virion morphology was noted. Higher-power view is in the panel under $\mathbf{D}$. ${ }^{*} P<$ $0.05,{ }^{* * *} P<0.01$.

double labeled for CD45 (red) and IGF2R (green). Whereas CD45 was distributed along the plasma membrane, IGF2R was concentrated in the Golgi area and in endosomal vesicles, showing the typical trans-Golgi pattern of mannose phosphate receptor expression. In addition to microglia, neurons also expressed abundant IGF2R but astrocytes showed considerably less IGF2R immunoreactivity (not shown).

We next examined whether HIV can increase the expression of IGF2R in microglia, by infecting the cultures with VSVg env HIV for 3 days and then immunoblotting for IGF2R $(n=3)$. The results interestingly showed that there was a trend for HIV infection to decrease the IGF2R expression, but this effect was not significant (Figure 4B). We next asked whether treatment of microglia with cytokines or TLR ligands could change the level of IGF2R expression. Western blot analysis was performed using five different cultures derived from different donor brains. Given the limited number of microglial cells that can be obtained from each brain, we used various cell stimuli which consisted of the following: proinflammatory cytokines (interleukin [IL]-1 $\beta$ or tumor necrosis factor $[\mathrm{TNF}] \alpha$ at $10 \mathrm{ng} / \mathrm{ml}$ ), anti-inflammatory (Th2) cytokines (IL-4, IL13 , or IL-10 at $10 \mathrm{ng} / \mathrm{ml}$ ), interferons (IFN $\gamma$ or IFN $\beta$ at 10 $\mathrm{ng} / \mathrm{ml}$ ), and the TLR ligands (LPS, $100 \mathrm{ng} / \mathrm{ml}$, poly IC: PIC 
A
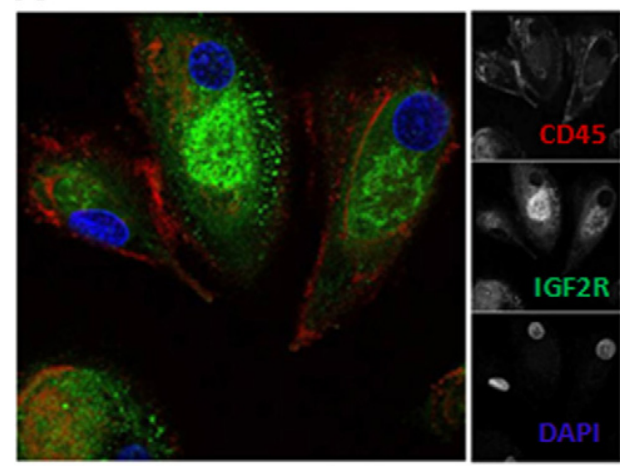

C

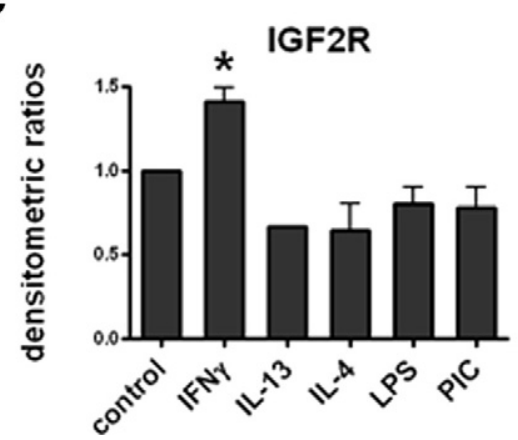

B

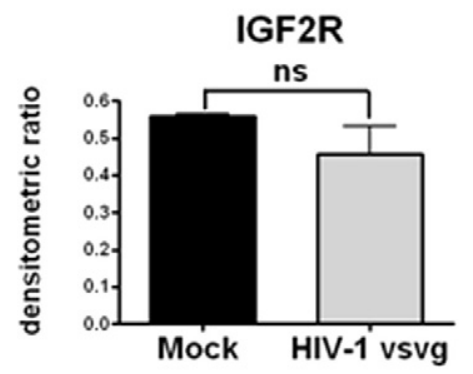

Figure 4. IFN $\gamma$ up-regulates IGF2R expression in microglia. A: Primary human fetal microglia in culture were examined for IGF2R expression by double immunofluorescence microscopy (CD 45 red; IGF2R green). They show typical trans Golgi distribution of IGF2R expression. B: IGF2R expression was compared in mock or HIV-infected microglial cultures by Western blot and densitometric analysis, as described in the text. There was slight decrease in IGF2R levels in HIV-infected microglia, but this difference was not significant $(P>0.05, n=3)$. C: Microglia were stimulated with various cytokines (10 ng/ $\mathrm{ml}$ ) or TLR ligands (LPS at $100 \mathrm{ng} / \mathrm{ml} ;$ PIC $=$ poly IC at $20 \mu \mathrm{g} / \mathrm{ml}$ ) for 24 hours then Western blot analysis was performed for IGF2R as described in the Materials and Methods. Densitometric ratios to housekeeping protein (vinculin or $\beta$-actin) were compared after normalizing to the IGF2R level in control microglial culture $(n \geq 3)$. Mean \pm SEM. ${ }^{*} P<0.05$, analysis of variance with Dunnett's posttest. D: Microglial cultures were subjected to a similar treatment as in $\mathbf{C}$ except that IGF2R expression was examined by Q-PCR. Mean \pm SEM. ${ }^{* * *} P<0.01$.
$20 \mu \mathrm{g} / \mathrm{ml}$ ). We observed that although individually many of these factors altered microglial IGF2R protein levels, the changes were minor and variable. We therefore performed statistical analysis on pooled normalized densitometric data for the treatment conditions tested at least three times. The results showed that IFN $\gamma$ alone significantly increased the expression of IGF2R $(P<0.05$, analysis of variance with Dennett's post test, Figure 4C), while others (IL-4, IL-13, LPS, or poly IC:PIC) did not. Additional microglial cases were subjected to IGF2R mRNA analysis by Q-PCR. These experiments again showed that IFN $\gamma$ (Th1 cytokine) but not the Th2 cytokines or TLR ligands increased IGF2R expression in microglia $(P<0.01$, Figure 4D).
A IGF2R (X10)

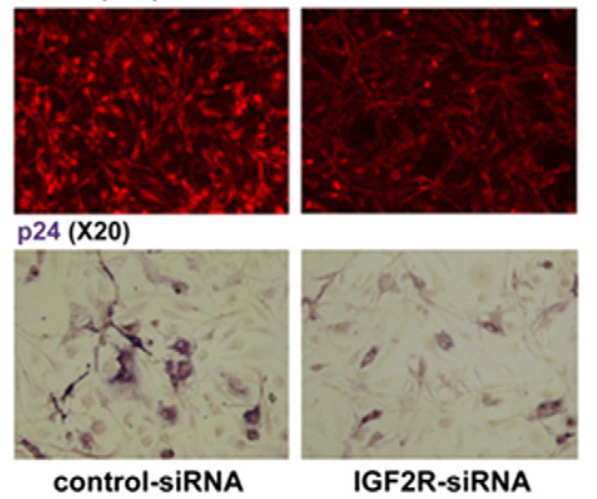

C
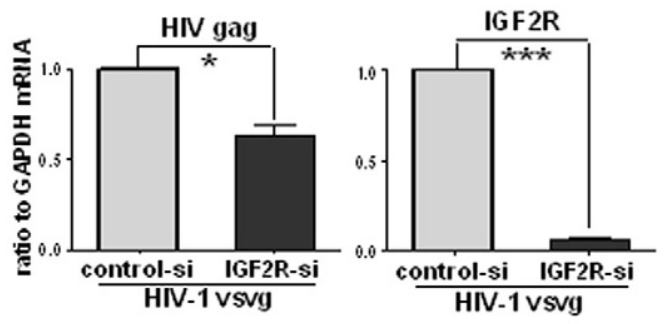

B

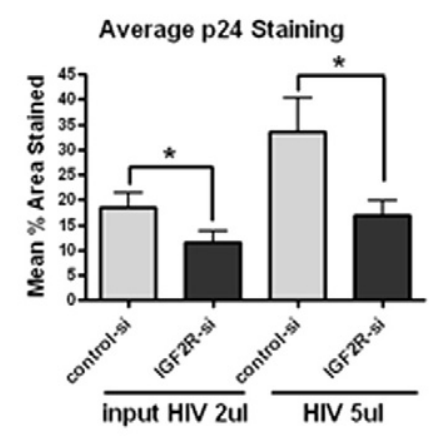

D

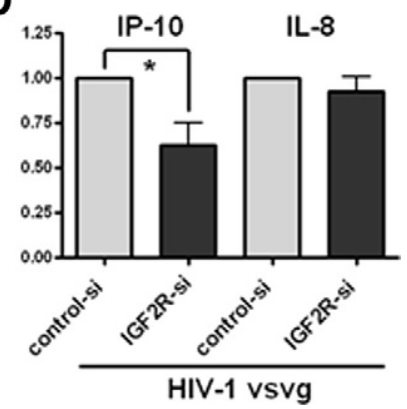

Figure 5. IGF2R siRNA decreases HIV infection and IP-10 production in human microglia. A: Primary human microglial cultures were transfected with IGF2R siRNA or control siRNA at 10 $\mathrm{nmol} / \mathrm{L}$ for 5 days then infected with VSVg env HIV for an additional 3-4 days. Immunofluorescence microscopy showed decrease in IGF2R expression (red) in specific siRNA treated cultures compared to control. In these cultures, HIV gag expression was also decreased as determined by immunostain for p24 (immunoperoxidase method, purple). B: Quantitative ImageJ analysis showed significant inhibition of p24 in IGF2R siRNA-treated microglial cultures (mean $\pm \mathrm{SEM}, P<0.05 t$-test) infected with two different input viral doses. C: Q-PCR analysis of HIVgag and IGF2R mRNA in microglial cultures treated with IGF2R siRNA and infected with HIV as in $\mathbf{A}$, showing marked knockdown of IGF2R expression and inhibition of HIV expression by IGF2R RNAi. ${ }^{*} P<0.05$, ${ }^{*} * * * 0.001$ ( $t$-test) $\mathbf{D}$ : The production of chemokines IP-10 and IL-8 was examined by ELISA in microglial cultures treated with IGF2R siRNA and infected with HIV as in $\mathbf{A}$. The production of IP-10 but not IL- 8 was significantly reduced by IGF2R RNAi $\left({ }^{*} P<0.05\right.$, $n=3, t$-test) 

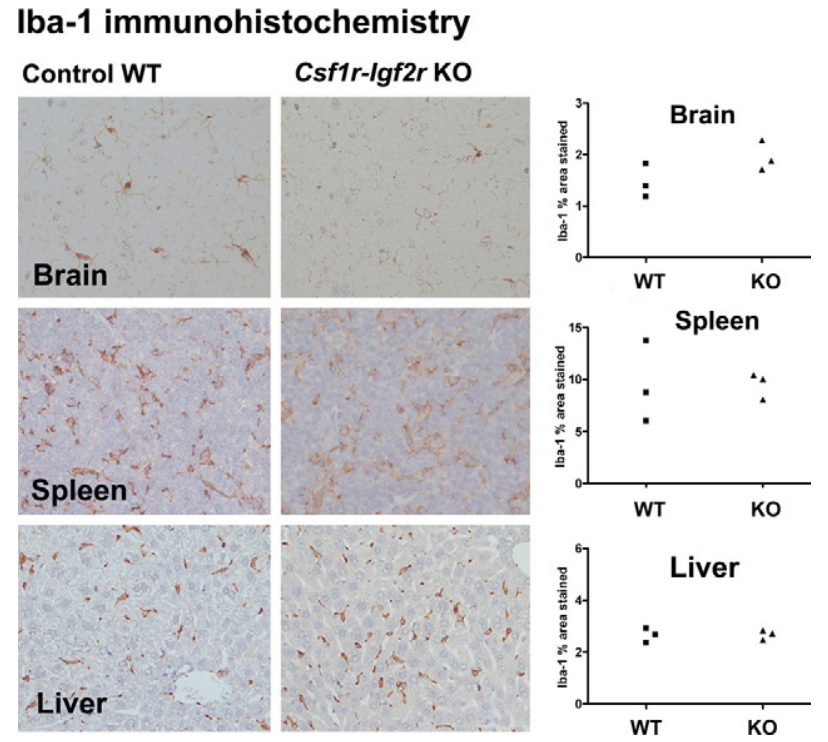

Figure 6. Characterization of Csf $1 r$-Igf $2 r$ KO mice (Iba- 1 immunohistochemistry). Iba-1 (a macrophage marker) immunohistochemistry was used to examine tissue macrophage populations in the brain, spleen, and liver of the WT (left column) and KO (right column) mice. In the brain, Iba-1 stained delicate ramified microglial cells, while in the spleen, numerous positive cells were present both in the white and red pulp. Kupffer cells were positive in the liver. Morphometric analyses by ImageJ from three mice each show no differences in the amount of Iba-1 stain. These results indicate that Csf $1 r$-driven Igf $2 r$ deletion did not alter tissue macrophages in an appreciable way.

\section{Role of IGF2R in HIV Infection of Human Microglia}

Having obtained the results that IGF2R KD epithelial cell lines have reduced HIV gag expression and HIV virion production, we next asked whether IGF2R plays a similar role in HIV production in human microglia, a cell type that is physiologically relevant. Microglia were transfected with siRNA specific to IGF2R or control siRNA (Smart Pool, Dharmacon) for five days then infected with VSVg env NL4-3 for additional 3-4 days. HIV gag expression was examined by p24 immunostain or by Q-PCR. IGF2R siRNA-transfected microglial cultures showed markedly reduced IGF2R expression by immunofluorescence (Figure $5 \mathrm{~A}$ ) and by Q-PCR (Figure 5C). HIV gag expression was significantly reduced in these cultures, as determined by HIV p24 stain (Figure 5B: ImageJ analysis, $n=6$ ) or by Q-PCR (Figure 5C: $n=3$ ), although the amount of reduction was less than IGF2R reduction. As we have previously determined that the Th1 chemokine IP-10 (CXCL10) was consistently induced in HIV-infected microglia, ${ }^{32,32}$ we tested the effect of IGF2R siRNA on IP-10 expression in these cultures. The results showed that IP-10 release from these cultures was significantly reduced by IGF2R $\mathrm{KD}$ as measured by ELISA, whereas no such change was observed for another $\alpha$-chemokine IL-8 (CXCL8) (Figure $5 D$ ). These results together demonstrate that IGF2R plays a significant role in microglia as a positive regulator of HIV replication and IP-10 production.

\section{Generation and Characterization of Csf1r-Igf2r KO Mice}

Mice with global deletion of lgf2r die perinatally due to organomegaly. Therefore, investigation of the role of IGF2R in mature animals requires a generation of conditional knockout. To examine the role of microglial IGF2R, we created macrophage-specific lgf2r knockout mice by crossing the Igf2r loxP mice ${ }^{14}$ with the Csf1r Cre mice (see Materials and Methods). The resulting Csf1r-lgf2r KO mice were normal in phenotype. Necropsy and routine histochemistry were performed on mice at 2-3 months of age. The brain, lungs, heart, thymus, spleen, liver, and kidneys were normal grossly and microscopically (H\&E: not shown). Iba-1 (a macrophage marker) immunohistochemistry was used to examine tissue macrophage populations and they showed no appreciable difference between KO and WT animals (Figure 6). These results indicate that Csf1r-driven Igfar deletion did not alter tissue macrophages in an appreciable way. The expression of IGF2R was also examined by immunohistochemistry (Figure 7). In the brain, IGF2R immunoreactivity was noted exclusively in neurons, and the neuronal IGF2R was comparable between WT and Csf1r-Igf2r KO (KO) mice. In the lungs, IGF2R expression was extensive and was present in the bronchial epithelial cells, alveolar septae, as well as macrophages. IGF2R-immunoreactive cells were very few in the spleen (Figure 7), kidney, or heart (not shown). The expression of IGF2R in WT and KO mice was examined quantitatively in the brain and spleen by Q-PCR (Figure 8, A and B), and this showed a statistically significant reduction in IGF2R mRNA in the spleen but not the brain of KO mice. Analysis of additional IGF family and related proteins revealed that IGF1 was significantly reduced in the spleen of KO mice (not shown). None of the changes in the brain, including GFAP, MPRcd, and Iba-1, were significant.

\section{HIV Replication in Bone Marrow-Derived Macrophages from Csf1r-Igf2r KO Mice}

Certain primary murine cells have been shown to be permissive to infection with HIV when pseudotyped with VSVg env. ${ }^{41}$ Therefore, to determine the effect of lgf2r KO in peripheral macrophages, we examined BMDM from Csf1r-lgf2r KO and WT mice. BMDM grown in the presence of M-CSF were infected with VSVg env HIV, then IGF2R and HIV gag expression were determined by QPCR. As shown in Figure 9, IGF2R expression was virtually abolished in macrophages from Csf1r-lgf2r KO mice, while the expression of IGF1, IGF1R, MPRcd, and Iba-1 mRNA were not altered. IGF2 mRNA was undetectable in either KO or WT culture (not shown). Importantly, HIV gag was highly expressed in murine macrophage cultures, with significant inhibition observed in lgf2r $\mathrm{KO}$ macrophages $(P<0.01)$ (Figure 9). 


\section{Control WT}
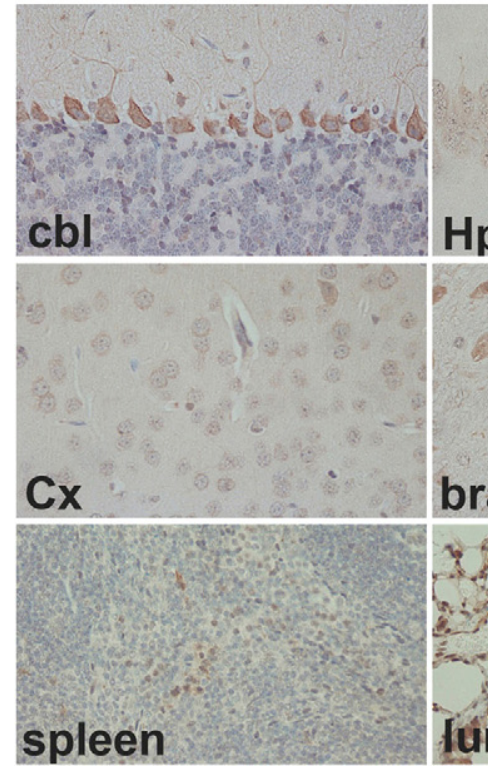
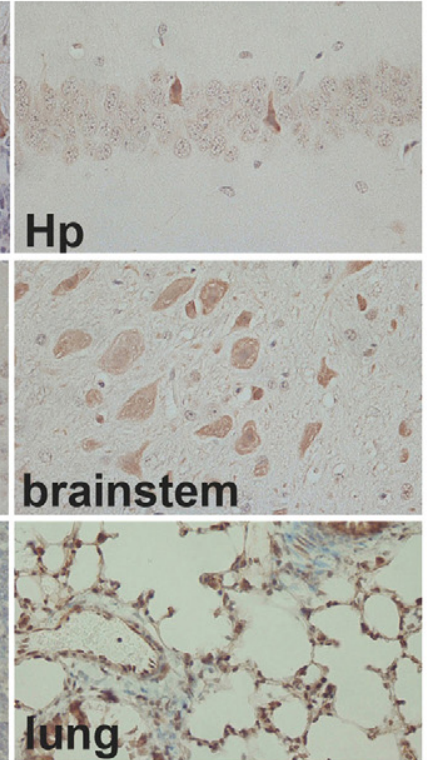

\section{Csf1r-lgf2r KO}
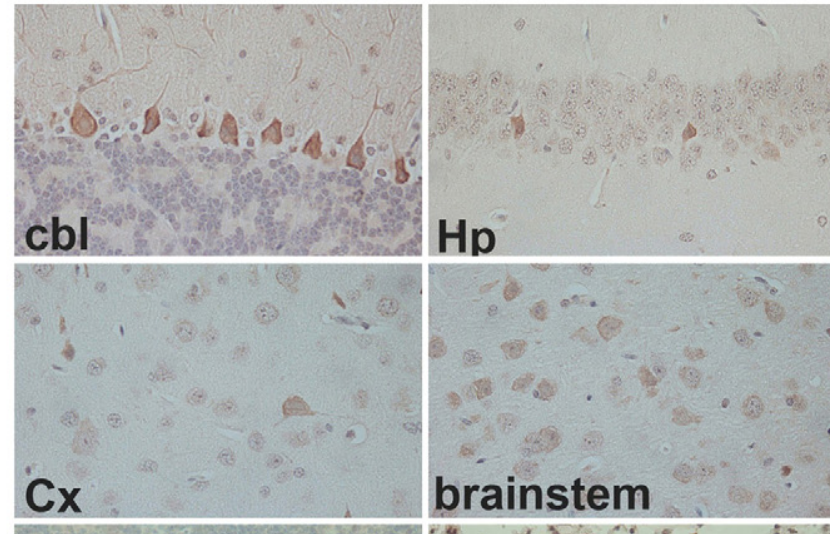

\section{brainstem}

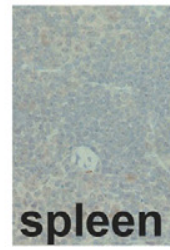

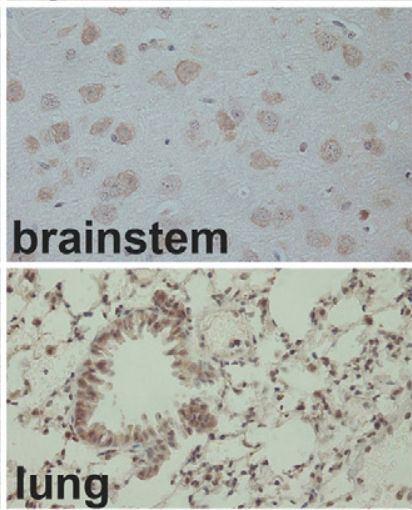

Figure 7. Characterization of Csf1r-Igf $2 r$ KO mice (IGF2R immunohistochemistry). In the brain, IGF2R immunoreactivity was noted exclusively in neurons with no appreciable difference between WT and KO (cbl: cerebellum, Hp: hippocampus, Cx: cortex and brainstem). Spleen had very few IGF2R-immunoreactive cells, while lungs showed strong IGF2R-immunoreactivity in bronchial epithelial cells, alveolar septae, as well as macrophages. Together, these results show that under normal conditions, IGF2R is expressed mostly in nonmacrophage populations. There are no appreciable differences in the IGF2R immunoreactivity between WT and Csf $1 r$-driven Igf $2 r$ KO mice.

\section{HIV Replication in Microglia and Astrocytes from Csf1r-Igf2r KO Mice}

Murine microglia and astrocyte cultures were also examined in a manner similar to BMDM. Cultures were established from neonates and were exposed to VSVg env HIV as described in the Materials and Methods, and then subjected to Q-PCR analysis (Figure 10, A and B). The results demonstrate that similar to macrophages, primary murine microglia and astrocytes sustained high levels of HIV replication and that microglia but not astrocytes from the Csf1r-lgf2r KO mice showed reduced IGF2R and HIV gag expression ${ }^{* * *} P<0.001$, ${ }^{* \star} P<0.01$ ).

Together, the mouse experiments demonstrated that i) primary murine macrophages, microglia, and astrocytes in culture are permissive to HIV infection when exposed to VSVg env HIV; ii) IGF2R expression is selectively reduced in macrophages and microglia derived from the Csf1r-lgf2r KO mice; and iii) HIV expression is suppressed in cells deficient in IGF2R. These results confirm the notion that IGF2R is a positive regulator of HIV expression.

\section{Intracerebral Injection of HIV to WT and Csf1r-Igf2r KO Mice}

To determine whether IGF2R has a similar HIV-enhancing role in vivo, we performed intracerebral injection of VSVg env HIV to WT and KO mice. When the brain tissues were examined by Q-PCR at 7 days post inoculation, neither WT nor KO brains showed detectable HIVgag (data not shown). However, HIV gag immunohistochemistry on tis- sue sections demonstrated focal p24 expression along the injection track in both WT and KO brains (Figure 11). Interestingly, in both of these brains, HIV p24 expression was limited to neurons, the only cell type with detectable IGF2R expression by immunohistochemistry (see Figure 7). Because mouse microglia in vivo (but not in vitro) lacked IGF2R expression, the lack of microglial infection might simply be a reflection of absent IGF2R expression. By contrast, the neuronal expression of both IGF2R and HIV gag in vivo strengthens the notion that IGF2R is a positive regulator of intracellular HIV replication.

\section{Discussion}

In the current study, we undertook a systematic investigation of IGF2R expression and function in HIV encephalitis and in the tissue culture and mouse models of HIVE. One of the most surprising findings of this study was that in human CNS, IGF2R was an inducible microglial protein whose expression increased from normally undetectable to robust expression (comparable to neuronal expression) at sites of microglial activation and HIV replication (microglial nodules). Neurons expressed high levels of IGF2R but the neuronal IGF2R immunoreactivity did not show an appreciable difference between normal and HIVE, indicating that IGF2R in neurons and microglia are under different regulatory control.

Despite low to undetectable levels of IGF2R in (normal) microglia in vivo, cultured microglia showed high basal level IGF2R expression. This may be due to an ongoing microglial lysosomal phagocytic activity in tissue culture, as well as high concentrations of IGF1 and IGF2 in fetal bovine serum to which cultured microglia are exposed. 
A Brain

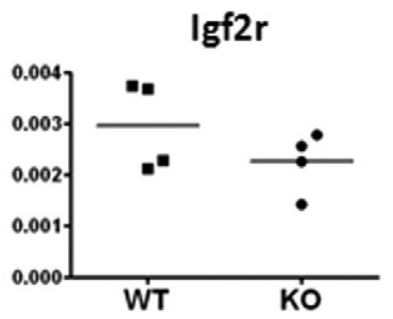

Iba-1

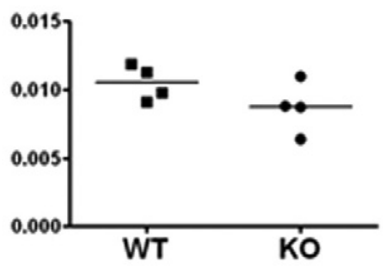

B Spleen

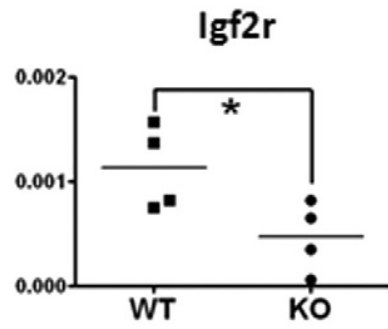

MPRed
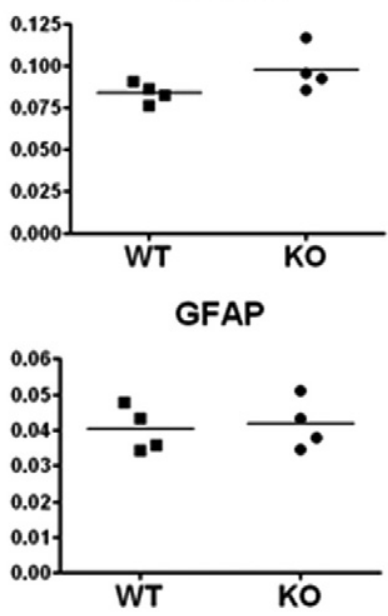

Iba-1

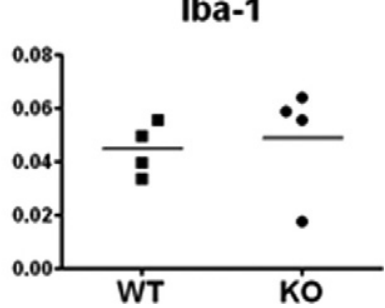

Figure 8. Characterization of Csf1r-Igf2 $r$ KO mice (Q-PCR of brain and spleen tissue). Further quantitative gene expression analysis was performed by Q-PCR of the brain (A) and spleen (B) tissue. IGF2R mRNA was reduced significantly in the spleen (but not brain) of KO mice ( ${ }^{*} P<0.05, t$-test). Iba- 1 levels were not different in either organ (bars = mean values). Analysis of additional IGF family and related proteins revealed that IGF1 was significantly reduced in the spleen of KO mice (not shown). None of the changes in the brain including GFAP and MPRcd were significant.

Even with high basal level expression, human microglia in vitro stimulated with IFN $\gamma$ showed further increase in IGF2R mRNA and protein, demonstrating that inflammatory cytokines can indeed increase microglial IGF2R. However, it is possible that our tissue culture study had missed other potentially important inflammatory mediators that may induce IGF2R expression in vivo, due to high baseline expression of IGF2R in tissue culture.

As we observe that IGF2R is induced by mannose-6phosphate itself (this study and data not shown), it is possible that IGF2R expression will increase under the conditions of increased lysosomal activity. In this context, it is of interest that recent proteomics studies have identified lysosomal enzymes (cathepsins) and related proteinases (cystatins) to be the ones most significantly altered in the CSF of cognitively impaired $\mathrm{HIV}^{+}$individuals. ${ }^{42}$ In vitro, HIV-infected mononuclear phagocytes display similar changes in cathepsins, cystatins, and other Iysosomal enzymes, ${ }^{43,44}$ suggesting that the altered metabolism of HIV-infected macrophages and microglia is central to the pathogenesis of HIV-associated neurocognitive disorder (HAND). Significant elevations of Iysosomal hydrolases and cathepsins have been found in earlier tissue-based studies HIVE and SIV encephalitis. ${ }^{45-47}$

\section{Bone marrow-derived macrophages}
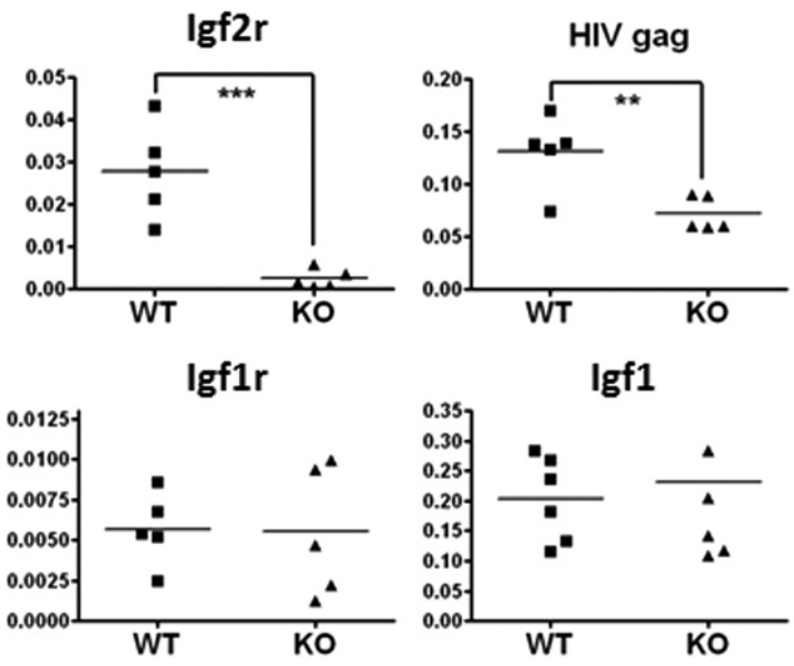

MPRcd
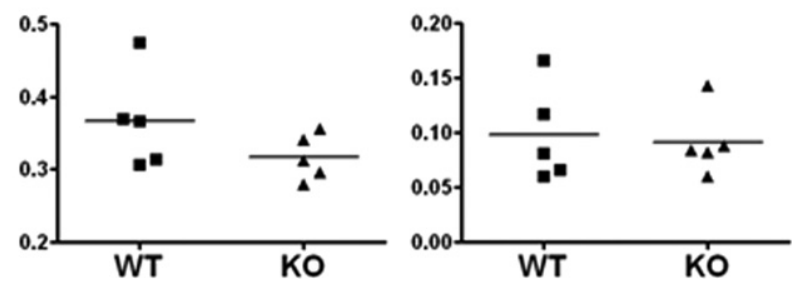

Figure 9. HIV replication in murine macrophages from Csf $1 r$-Igf $2 r \mathrm{KO}$ mice Bone marrow-derived macrophages (BMDM) were isolated from the WT or $\mathrm{KO}$ mice and cultured in the presence of M-CSF as described in the Materials and Methods. Macrophages were infected with VSVg env HIV for 4 days and then analyzed for HIV gag and IGF family and related proteins by Q-PCR. Transcript levels for IGF2R and HIV gag were significantly reduced in KO macrophages $\left({ }^{* *} P<0.01,{ }^{* * *} P<0.001\right)$. IGF1R, IGF1, MPRcd, and Iba-1 were not significantly altered. IGF2 was not detected (not shown).

It is therefore of great significance that IGF2R, a protein critically involved in the lysosomal function, is increased in microglia and macrophages in HIVE (this study). In addition to strengthening the notion that microglial lysosomal integrity might be important in the pathogenesis of HAND, these findings also indicate that increased endosomal and lysosomal activity (in addition to inflammatory cytokines such as IFN $\gamma$ ) may also contribute to the enhanced expression of IGF2R in the CNS.

In an effort to elucidate possible functions of increased IGF2R in microglia observed in HIVE, we investigated its role in HIV replication. We used several experimental systems ranging from MeWo cell lines with stable IGF2R knockdown, to primary human microglia transiently expressing IGF2R siRNA, to mice with Csf1r promoterdriven macrophage-specific lgf2r knockout. For HIV infection, we have used a single-cycle competent, VSVg env-pseudotyped NL4-3 construct that has intact HIV Nef and Vpr genes, ${ }^{33}$ to obtain fast and efficient replication in microglia. The use of the modified HIV constructs also enabled efficient replication in murine cells. The results of these experiments demonstrated that IGF2R enhances the level of HIV expression, a novel function for IGF2R. Specifically, in four separate accounts (MeWo, 


\section{A Murine Microglia}
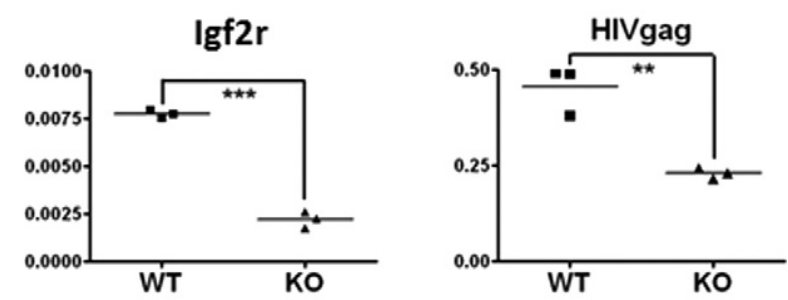

\section{B Murine Astrocytes}
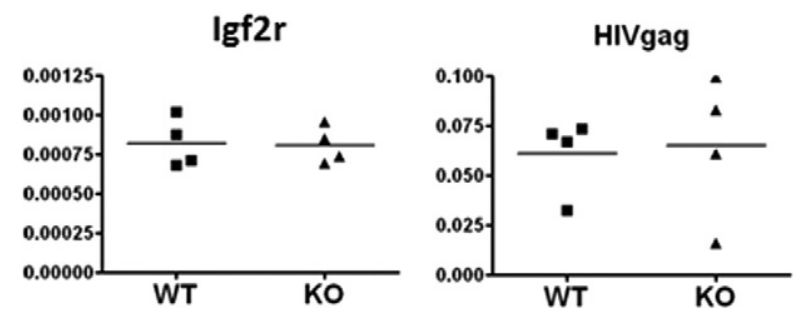

Figure 10. HIV replication in murine microglia and astrocytes from Csf1r Igf $2 r \mathrm{KO}$ mice. Microglia (A) and astrocytes $(\mathbf{B})$ were cultured from neonates as described in the Materials and Methods and then subjected to HIV infection and Q-PCR analysis as in Figure 9 legend. The results demonstrate that microglia but not astrocytes from the Csf $1 r$-Igf $2 r$ KO mice show reduction of IGF2R expression and HIV gag expression compared to WT cells.

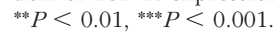

human and murine microglia, and murine macrophages), suppression of IGF2R expression also led to significant and consistent suppression of HIV gag expression. These results together show that once HIV entry is achieved, the intracellular HIV life cycle critically depends on the cellular endosomal and lysosomal machinery and that IGF2R positively contributes to the productive infection of HIV. The specific molecular mechanism(s) underlying this observation is unknown. Because HIV proteins do not bear M6P residues, increased HIV production by IGF2R must be through indirect mechanisms of facilitating intracellular HIV protein trafficking. Indeed, recent studies have demonstrated the importance of endosomes and vesicular sorting proteins in HIV biogenesis in various cell models including primary macrophages. ${ }^{48,49}$ In macrophages, HIV has been shown to bud into the late endosomal compartment called "multivesicular bodies," although the types and the specific details of the intracellular compartments involved in HIV biogenesis are still debated. Additionally, it is curious that IGF2R was not identified in recent genome-wide surveys of host genes involved in HIV replication. ${ }^{50-52}$ Four screens have been performed to date and the results of these studies are surprisingly different from each other, suggesting that conditions and readouts of the screens affect the identities of the hits recovered.

We have generated mice with Csf-1r promoter-driven deletion of lgf2r to study macrophage and microgliaspecific functions of this receptor in vivo. The Csf1r promoter, similar to other macrophage-specific promoters such as CD11b and lysozyme promoters, are common to all myeloid cells. Our Csf1r-lgf2r KO mice showed normal development and normal phenotype, suggesting that myeloid IGF2R (at least that which is Csf1r-driven) was not essential for fetal development. There was no obvious change in the systemic and brain macrophage populations, as examined by $\mathrm{lba}-1$ immunohistochemistry. Csf1r-lgf2r KO mice should be useful for future investigation of macrophage IGF2R function in innate immunity and inflammation.

We had anticipated the usefulness of the Csf1r-lgf2r $\mathrm{KO}$ mice as an in vivo model of HIVE and that the use of VSVg env HIV would enable quantification of replicating HIV in all cell types of the mouse brain. Interestingly, while VSVg env HIV replicated efficiently in cultures of

\section{HIV p24 Immunohistochemistry}
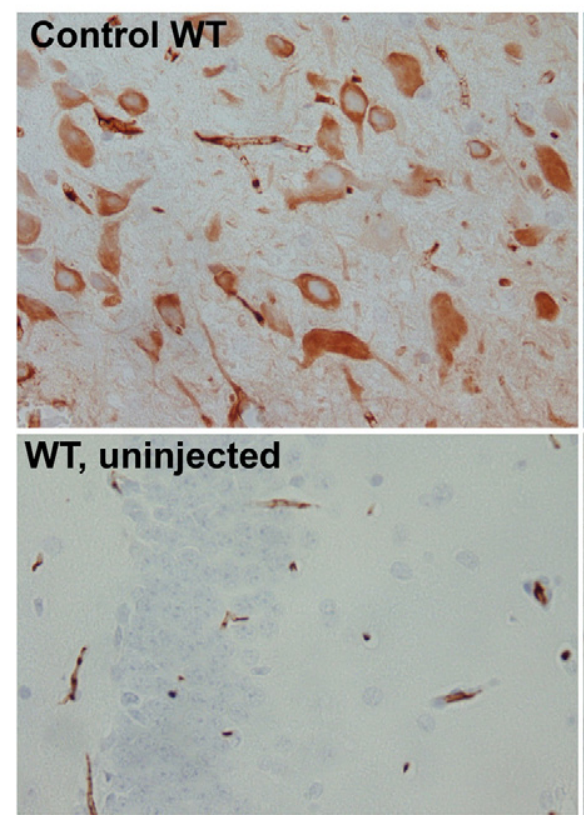
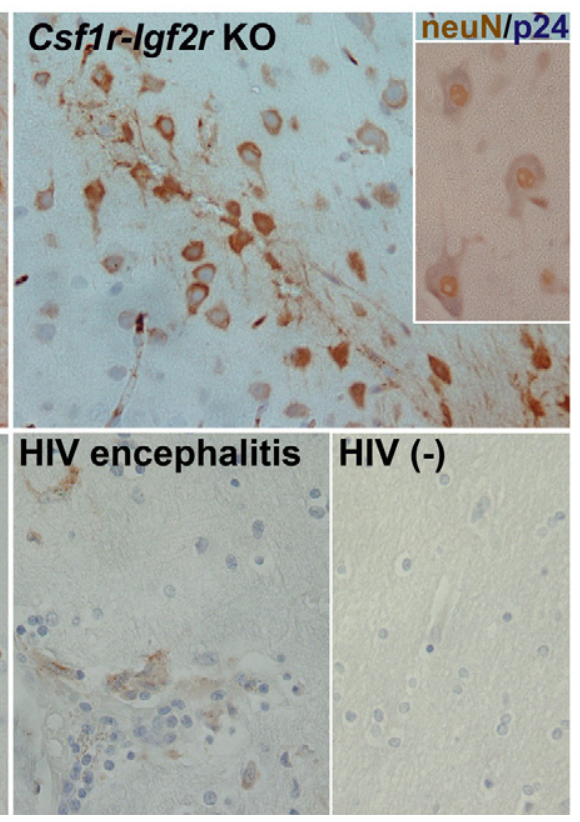

Figure 11. HIV $\mathrm{p} 24$ in WT and Csf1r-Igf $2 r$ KO mouse brains inoculated with VSVg env HIV. Brain tissues of the mice injected with VSVg env HIV are immunostained for HIV gag (p24) 7 days later. In both WT and KO mouse brains, only the neurons along the needle track are positive for p24 (top panels). Note the linear needle track (top right). The neuronal identity of HIV-infected cells is confirmed by double label immunohistochemistry for neuN (neuronal nuclei brown) and HIV p24 (cytoplasm: blue) (inset top right). Neurons away from the injection site and in uninjected brains are negative for p24 (bottom left). Vessels in mouse brains are positive due to the presence of mouse IgG reactive to the secondary antibody. Controls for HIV p24 consisted of human brain with HIV encephalitis (microglia and multinucleated giant cells positive) and a normal HIV (-) brain (no reactivity) (bottom right panels). All singly labeled sections were lightly counterstained with hematoxylin. 
primary mouse macrophages, microglia, and astrocytes, as reported, ${ }^{41}$ the only cell type expressing HIV gag after intracerebral injection of VSVg env HIV in vivo was neurons. These results indicate that murine glial cells in vivo may have additional barriers (possibly including the lack of IGF2R expression) to HIV replication. Because neurons are the only cell type normally expressing abundant IGF2R in these mice, these results are an affirmation of our hypothesis that intracellular HIV replication is critically dependent on IGF2R expression. These results also bring out the (generally recognized) difficulties of adopting mouse models for HIV studies. They highlight that the most significant block for HIV infection in mammalian cells (including human) might be the entry step due to lack of specific HIV receptor/coreceptor expression because once the entry step is bypassed virtually all cells are capable of supporting HIV replication (that is, at least in vitro). The parallel between IGF2R expression and the ability to support intracellular HIV replication found in neurons in the mouse brain is interesting and suggests that microglial infection by HIV in human brain may require their prior activation to acquire the expression of IGF2R.

Our results have implications for the pathogenesis of HAND. The dramatic up-regulation of IGF2R in activated microglia in vivo may have several undesirable consequences. First, IGF2R, as shown repeatedly in this study, could facilitate HIV expression in microglia, contributing to viral persistence and spread within the CNS. Second, IGF2R may also control induction of microglial inflammatory genes. For example, we show that IP-10 is acutely induced in VSVg env HIV-infected microglia ${ }^{32}$ and that IP-10 production in these cultures is suppressed by IGF2R siRNA (this study). IP-10 or signaling through its cognate receptor CXCR3 has been shown to contribute to HIV-induced neurodegenerative mechanisms, ${ }^{53,54}$ suggesting that IGF2R might contribute to HIV-mediated neurodegeneration. Third, up-regulation of IGF2R in activated glia could potentially serve as a growth factor "sink" mechanism by which IGF family peptides are internalized and degraded, further serving as an agent of neural damage. Future studies aiming at validating these hypotheses might be of significant value, as they might enable identification of a novel biomarker or a therapeutic target.

\section{Acknowledgments}

We thank Dr. Susan Morgello (Mt Sinai School of Medicine, NY) of the National NeuroAIDS Tissue Consortium for postmortem human brain tissues, Dr. Brad Poulos (Einstein Human Fetal Tissue Repository) for fetal brain tissues, Dr. Michael Gershon (Columbia University, NY) for the MeWo cell lines, Dr. Carolyn Scott (University of Sidney, Australia) for the IGF2R antibody, and Dr. Maurizio Federico (Istituto Superiore di Sanita, Rome, Italy) for the HIV constructs. We are especially grateful to Dr. Peter Lobel (Rutgers University, NJ) for the IGF2R antibody and for the countless advice and discussions. We also thank Marc Vargas (Einstein Transgenic Mouse Facility) for as- sistance with the lgf2r KO mouse work, and Drs. Celia F. Brosnan and Joan W. Berman for helpful discussions.

\section{References}

1. Russo VC, Gluckman PD, Feldman EL, and Werther GA: The insulinlike growth factor system and its pleiotropic functions in brain. Endocr Rev 2005, 26:916-943

2. Bondy $C A$ and Cheng $C M$ : Signaling by insulin-like growth factor 1 in brain. Eur J Pharmacol 2004, 490:25-31

3. Baxter RC: Insulin-like growth factor (IGF)-binding proteins: interactions with IGFs and intrinsic bioactivities. Am J Physiol Endocrinol Metab 2000, 278:E967-E976

4. Denley A, Cosgrove LJ, Booker GW, Wallace JC, and Forbes BE: Molecular interactions of the IGF system. Cytokine Growth Factor Rev 2005, 16:421-439

5. Hawkes C, Jhamandas JH, Harris KH, Fu W, MacDonald RG, and Kar $\mathrm{S}$ : Single transmembrane domain insulin-like growth factor-II/mannose-6-phosphate receptor regulates central cholinergic function by activating a G-protein-sensitive, protein kinase C-dependent pathway. J Neurosci 2006, 26:585-596

6. Ghosh P, Dahms NM, and Kornfeld S: Mannose 6-phosphate receptors: new twists in the tale. Nat Rev Mol Cell Biol 2003, 4:202-212

7. Lau MM, Stewart CE, Liu Z, Bhatt H, Rotwein P, and Stewart CL: Loss of the imprinted IGF2/cation-independent mannose 6-phosphate receptor results in fetal overgrowth and perinatal lethality. Genes Dev 1994, 8:2953-2963

8. Ong K, Kratzsch J, Kiess W, Costello M, Scott C, and Dunger D: Size at birth and cord blood levels of insulin, insulin-like growth factor I (IGF-I). IGF-II, IGF-binding protein-1 (IGFBP-1), IGFBP-3, and the soluble IGF-II/mannose-6-phosphate receptor in term human infants The ALSPAC Study Team Avon Longitudinal Study of Pregnancy and Childhood J Clin Endocrinol Metab 2000, 85:4266-4269

9. Sohar I, Sleat D, Gong LC, Ludwig T, and Lobel P: Mouse mutants lacking the cation-independent mannose 6-phosphate/insulin-like growth factor II receptor are impaired in lysosomal enzyme transport: comparison of cation-independent and cation-dependent mannose 6-phosphate receptor-deficient mice. Biochem J 1998, 330 (Pt 2):903-908

10. Qian M, Sleat DE, Zheng H, Moore D, and Lobel P: Proteomic analysis of serum from mutant mice reveals lysosomal proteins selectively transported by each of the two mannose 6-phosphate receptors. Mol Cell Proteomics 2008, 7:58-70

11. Ewton DZ, Falen SL, and Florini JR: The type II insulin-like growth factor (IGF) receptor has low affinity for IGF-I analogs: pleiotypic actions of IGFs on myoblasts are apparently mediated by the type I receptor. Endocrinology 1987, 120:115-123

12. Ludwig T, Eggenschwiler J, Fisher P, D'Ercole AJ, Davenport ML, and Efstratiadis A: Mouse mutants lacking the type 2 IGF receptor (IGF2R) are rescued from perinatal lethality in Igf2 and Igf1r null backgrounds. Dev Biol 1996, 177:517-535

13. Wang ZQ, Fung MR, Barlow DP, and Wagner EF: Regulation of embryonic growth and lysosomal targeting by the imprinted Igf2/Mpr gene. Nature 1994, 372:464-467

14. Wylie AA, Pulford DJ, Vie-Wylie AJ, Waterland RA, Evans HK, Chen YT, Nolan CM, Orton TC, and Jirtle RL: Tissue-specific inactivation of murine M6P/IGF2R. Am J Pathol 2003, 162:321-328

15. Hawkes $C$ and Kar S: The insulin-like growth factor-II/mannose-6phosphate receptor: structure, distribution and function in the central nervous system. Brain Res Brain Res Rev 2004, 44:117-140

16. Wilczak N, De BP, Luiten P, Geerts A, Teelken A, and De KJ: Insulinlike growth factor II receptors in human brain and their absence in astrogliotic plaques in multiple sclerosis. Brain Res 2000, 863: 282-288

17. Kar S, Poirier J, Guevara J, Dea D, Hawkes C, Robitaille Y, and Quirion R: Cellular distribution of insulin-like growth factor-II/mannose-6-phosphate receptor in normal human brain and its alteration in Alzheimer's disease pathology. Neurobiol Aging 2006, 27:199-210

18. Strickler HD, Fazzari M, Kovacs A, Isasi C, Napolitano LA, Minkoff $H$, Gange S, Young M, Sharp GB, Kaplan RC, Cohen M, Gunter MJ, Harris TG, Yu H, Schoenbaum E, Landay AL, and Anastos K: Asso- 
ciations of insulin-like growth factor (IGF)-I and IGF-binding protein-3 with HIV disease progression in women. J Infect Dis 2008, 197:319-327

19. Frost RA, Fuhrer J, Steigbigel R, Mariuz P, Lang CH, and Gelato MC: Wasting in the acquired immune deficiency syndrome is associated with multiple defects in the serum insulin-like growth factor system. Clin Endocrinol (Oxf) 1996, 44:501-514

20. Helle SI, Ueland T, Ekse D, Froland SS, Holly JM, Lonning PE, and Aukrust P: The insulin-like growth factor system in human immunodeficiency virus infection: relations to immunological parameters, disease progression, and antiretroviral therapy. J Clin Endocrinol Metab 2001, 86:227-233

21. Baricevic I, Nedic O, Nikolic JA, and Nedeljkovic J: The insulin-like growth factor system in the circulation of patients with viral infections. Clin Chem Lab Med 2004, 42:1127-1131

22. Sui Y, Potula R, Pinson D, Adany I, Li Z, Day J, Buch E, Segebrecht $J$, Villinger F, Liu Z, Huang M, Narayan O, and Buch S: Microarray analysis of cytokine and chemokine genes in the brains of macaques with SHIV-encephalitis. J Med Primatol 2003, 32:229-239

23. Wang $J$ and Gabuzda D: Reconstitution of human immunodeficiency virus-induced neurodegeneration using isolated populations of human neurons, astrocytes, and microglia and neuroprotection mediated by insulin-like growth factors. J Neurovirol 2006, 12:472-491

24. Digicaylioglu M, Garden G, Timberlake S, Fletcher L, and Lipton SA: Acute neuroprotective synergy of erythropoietin and insulin-like growth factor I. Proc Natl Acad Sci USA 2004, 101:9855-9860

25. de la Monte SM and Wands JR: Review of insulin and insulin-like growth factor expression, signaling, and malfunction in the central nervous system: relevance to Alzheimer's disease. J Alzheimers Dis 2005, 7:45-61

26. Cosenza-Nashat MA, Kim MO, Zhao ML, Suh HS, and Lee SC: CD45 isoform expression in microglia and inflammatory cells in HIV-1 encephalitis. Brain Pathol 2006, 16:256-265

27. Cosenza-Nashat M, Zhao ML, Suh HS, Morgan J, Natividad R, Morgello S, and Lee SC: Expression of the translocator protein of $18 \mathrm{kDa}$ by microglia, macrophages and astrocytes based on immunohistochemical localization in abnormal human brain. Neuropathol Appl Neurobiol 2009, 35:306-328

28. Chen JJ, Zhu Z, Gershon AA, and Gershon MD: Mannose 6-phosphate receptor dependence of varicella zoster virus infection in vitro and in the epidermis during varicella and zoster. Cell 2004, 119:915-926

29. Lee SC, Liu W, Brosnan CF, and Dickson DW: Characterization of human fetal dissociated CNS cultures with an emphasis on microglia. Lab Invest 1992, 67:465-475

30. Lee SC, Collins M, Vanguri P, and Shin ML: Glutamate differentially inhibits the expression of class II MHC antigens on astrocytes and microglia. J Immunol 1992, 148:3391-3397

31. Song X, Shapiro S, Goldman DL, Casadevall A, Scharff M, and Lee SC: Fcgamma receptor I- and III-mediated macrophage inflammatory protein 1alpha induction in primary human and murine microglia. Infect Immun 2002, 70:5177-5184

32. Suh HS, Zhao ML, Choi N, Belbin TJ, Brosnan CF, and Lee SC: TLR3 and TLR4 are innate antiviral immune receptors in human microglia: role of IRF3 in modulating antiviral and inflammatory response in the CNS. Virology 2009, 392:246-259

33. Federico M, Percario Z, Olivetta E, Fiorucci G, Muratori C, Micheli A, Romeo G, and Affabris E: HIV-1 Nef activates STAT1 in human monocytes/macrophages through the release of soluble factors. Blood 2001, 98:2752-2761

34. Rivieccio MA, Suh HS, Zhao Y, Zhao ML, Chin KC, Lee SC, and Brosnan CF: TLR3 ligation activates an antiviral response in human fetal astrocytes: a role for viperin/cig5. J Immunol 2006, 177:47354741

35. Suh HS, Zhao ML, Rivieccio M, Choi S, Connolly E, Zhao Y, Takikawa $\mathrm{O}$, Brosnan CF, and Lee SC: Astrocyte indoleamine 2, 3 dioxygenase (IDO) is induced by the TLR3 ligand poly IC: mechanism of induction and role in anti-viral response. J Virol 2007, 81:9838-9850
36. Lee SC, Liu W, Dickson DW, Brosnan CF, and Berman JW: Cytokine production by human fetal microglia and astrocytes: differential induction by LPS and IL-1b. J Immunol 1993, 150:2659-2667

37. Lee SC, Hatch WC, Liu W, Kress Y, Lyman WD, and Dickson DW: Productive infection of human fetal microglia by HIV-1. Am J Pathol 1993, 143:1032-1039

38. Bhavsar JH, Remmler J, and Lobel P: A method to increase efficiency and minimize anomalous electrophoretic transfer in protein blotting. Anal Biochem 1994, 221:234-242

39. Costello M, Baxter RC, and Scott CD: Regulation of soluble insulinlike growth factor II/mannose 6-phosphate receptor in human serum: measurement by enzyme-linked immunosorbent assay. J Clin Endocrinol Metab 1999, 84:611-617

40. Gibellini D, Gardini F, Vitone F, Schiavone P, Furlini G, and Re MC: Simultaneous detection of HCV and HIV-1 by SYBR Green real time multiplex RT-PCR technique in plasma samples. Mol Cell Probes 2006, 20:223-229

41. Nitkiewicz J, Chao W, Bentsman G, Li J, Kim SY, Choi SY, Grunig G, Gelbard H, Potash MJ, and Volsky DJ: Productive infection of primary murine astrocytes, lymphocytes, and macrophages by human immunodeficiency virus type 1 in culture. J Neurovirol 2004, 10:400-408

42. Laspiur JP, Anderson ER, Ciborowski P, Wojna V, Rozek W, Duan F, Mayo R, Rodriguez E, Plaud-Valentin M, Rodriguez-Orengo J, Gendelman HE, and Melendez LM: CSF proteomic fingerprints for HIV-associated cognitive impairment. J Neuroimmunol 2007, 192:157-170

43. Luo X, Carlson KA, Wojna V, Mayo R, Biskup TM, Stoner J, Anderson $J$, Gendelman HE, and Melendez LM: Macrophage proteomic fingerprinting predicts HIV-1-associated cognitive impairment. Neurology 2003, 60:1931-1937

44. Ciborowski P, Kadiu I, Rozek W, Smith L, Bernhardt K, Fladseth M, Ricardo-Dukelow M, and Gendelman HE: Investigating the human immunodeficiency virus type 1-infected monocyte-derived macrophage secretome. Virology 2007, 363:198-209

45. Gelman BB, Wolf DA, Rodriguez-Wolf M, West AB, Haque AK, and Cloyd M: Mononuclear phagocyte hydrolytic enzyme activity associated with cerebral HIV-1 infection. Am J Pathol 1997, 151:1437-1446

46. Roberts ES, Zandonatti MA, Watry DD, Madden LJ, Henriksen SJ, Taffe MA, and Fox HS: Induction of pathogenic sets of genes in macrophages and neurons in NeuroAIDS. Am J Pathol 2003, 162:2041-2057

47. Gelman BB, Soukup VM, Holzer CE, III, Fabian RH, Schuenke KW, Keherly MJ, Richey FJ, and Lahart CJ: Potential role for white matter Iysosome expansion in HIV-associated dementia. J Acquir Immune Defic Syndr 2005, 39:422-425

48. Marsh M and Thali M: HIV's great escape. Nat Med 2003, 9:1262-1263

49. Kramer B, Pelchen-Matthews A, Deneka M, Garcia E, Piguet V, and Marsh M: HIV interaction with endosomes in macrophages and dendritic cells. Blood Cells Mol Dis 2005, 35:136-142

50. Brass AL, Dykxhoorn DM, Benita Y, Yan N, Engelman A, Xavier RJ, Lieberman $\mathrm{J}$, and Elledge SJ: Identification of host proteins required for HIV infection through a functional genomic screen. Science 2008, 319:921-926

51. Goff SP: Knockdown screens to knockout HIV-1. Cell 2008, 135:417-420

52. Kok KH, Lei T, and Jin DY: siRNA and shRNA screens advance key understanding of host factors required for HIV-1 replication. Retrovirology 2009, 6:78

53. Sui $Y$, Potula R, Dhillon N, Pinson D, Li S, Nath A, Anderson C Turchan J, Kolson D, Narayan O, and Buch S: Neuronal apoptosis is mediated by CXCL10 overexpression in simian human immunodeficiency virus encephalitis. Am J Pathol 2004, 164:1557-1566

54. Vergote D, Butler GS, Ooms M, Cox JH, Silva C, Hollenberg MD, Jhamandas $\mathrm{JH}$, Overall CM, and Power C: Proteolytic processing of SDF-1alpha reveals a change in receptor specificity mediating HIVassociated neurodegeneration. Proc Natl Acad Sci USA 2006, 103:19182-19187 